- Quantias recebidas de boa fé em virtude de errônea interpretaçâo da lei e posterior mudança de critério não precisam ser propostas.

- Pagamento feito mediante liminar posteriormente cassada configura pagamento indevido sujeito a reposição.

\author{
Presidência da República \\ Advocacia Geral da União \\ Parecer n. GQ 161
}

PROCESSO № 00400.013771/95-34

ORIGEM: Ministério do Trabalho.

ASSUNTO: Reposições devidas ao erário por servidores públicos. Proposta de mudança na orientação da extinta Consultoria-Geral da República e mantida por esta Instituição. Reposições devidas em virtude de decisão judicial que, cassando liminar, julgou improcedente a açāo proposta por servidores.

\section{Parecer $n^{2}$ GQ - 161}

Adoto, para os fins do art. 41 da Lei Complementar $\mathrm{n}^{2} 73$, de 10 de fevereiro de 1993 , o anexo PARECER № AGU/MF-05/98, de 3 de agosto de 1998, da lavra da eminente Consultora da União, Dra. MIRTô FRAGA, e submeto-o ao EXCELENTÍSSIMO SENHOR PRESIDENTE DA REPÚBLICA, para os efeitos do art. 40 da referida Lei Complementar.
Brasília, 1 de setembro de 1998

GERALDO MAGELA DA CRUZ QUINTÃO, Advogado-Geral da União

PARECER No AGU/MF - 05/98 (Anexo ao Parecer GQ-161) PROCESSO №: 00400.013771/95-34. INTERESSADO: Ministério do Trabalho.

ASSUNTO: Reposições devidas ao erário por servidores públicos. Proposta de mudança na orientação da extinta Consultoria-Geral da República e mantida por esta Instituição. Reposições devidas em virtude de decisão judicial, que, cassando liminar, julgou improcedente a ação proposta por servidores.

EMENTA: A Lei n 8.112, de 1990, não desautoriza a orientação até agora observada de que as quantias recebidas "indevidamente", de boa fé, em virtude de errônea interpretaçāo da lei pela Administração e posterior mudança de critério Jurídico adotado, não 
precisam ser repostas. mesmo quando desconstituído $o$ ato. Conceito de pagamento indevido. Os pagamentos feitos em consequiência de liminares, posteriormente cassadas por decisōes judiciais definitivas, são pagamentos indevidos e estāo sujeitos à reposição, uma vez que não se enquadram na orientação adotada pela $A G U$.

\section{PARECER}

Com o Ofício CJ/MTb $n^{2} 43$, de 12 de novembro de 1995, o Sr. Consultor Jurídico do Ministério do Trabalho solicitou pronunciamento sobre a questão das reposições devidas ao erário por servidores públicos.

2. Na NOTA No AGU/JV -16/95, de 16 de novembro de 1995, a ilustre, então Consultora da União no exercício da Coordenação e hoje Secretária-Geral de Consultoria, Dra. Maria Jovita Wolney Valente, observou:

"Embora a matéria não tenha sido submetida ao Advogado-Geral da União na forma estabelecida na Lei Complementar $n^{2} 73$, de 10.12.93 (art. 39), reveste-se ela de tal magnitude para o Erário Público que, certamente, o alto descortino de Vossa Excelência, em homenagem à finalidade, relevará a forma $e$ determinará o estudo da matéria, objetivando "fixar a interpretação da Constituição, das leis, dos tratados e demais atos normativos, a ser uniformemente seguida pelos órgãos e entidades da Administraçāo Federal" $e$ "... garantir a correta aplicação das leis... (art. 4e, X e XI, da Lei Complementar ne 73, de 1993)."

3. A proposta foi aprovada. Em 24 de março de 1998, os autos me foram redistribuidos $\mathrm{em}$ consequiência da exoneração do Consultor da União ao qual, em novembro de 1995 , coube o exame do assunto.

\section{I - A QUESTÃO A SER ANALISADA}

4. O ilustre Consultor Jurídico do Ministério do Trabalho menciona a orientação da antiga Secretaria de Administração Federal, hoje Ministério da Administraçāo Federal e Reforma do Estado, "considerando indevida a reposição por parte de quem recebeu vantagens de 'boa fé', ou diante do caráter 'alimentar' dos vencimentos - expressões que, em si, permitem diferentes interpretaçōes e orientações, no bojo dos diversos Ministérios e Secretarias da Administraçāo Federal."

5. A orientação da antiga SAF, expressa no Parecer $n^{2} 179 / 91$, de 16 de julho de 1991, do Departamento de Recursos Humanos, menciona $o$ art. 46 da Lei $n^{2} 8.112$, de 10 de dezembro de 1990, e a Lei $\mathrm{n}^{2} 8.177$, de 1991, e manda observar, o Parecer da extinta Consultoria-Geral da República n CR/SA-21, de 9 de agosto de 1988, publicado no Diário Oficial da União de 18 de agosto do mesmo ano e segundo o qual, o servidor que, de presumida boa fé, venha a receber vantagem financeira em decorrência de errônea interpretação ou aplicação da norma legal por parte da Administração, não está obrigado a devolver o que recebeu indevidamente. $O$ Parecer da extinta Consultoria-Geral da República acrescenta: "Além do que, pagos como salário, têm caráter alimentar e, mesmo quando indevidos não estão sujeitos à reposição."

6. Questiona o Sr. Consultor Jurídico do Ministério do Trabalho a validade da observância, pela extinta SAF, da orientação da antiga Consultoria-Geral da República, uma vez que, posteriormente a ela, foi promulgada a Lei $\mathrm{n}^{2} 8.112$, de 10 de dezembro de 1990 , cujo artigo 46 restaria sem qualquer eficácia. Menciona, ainda, o Decreto $n^{2} 1.502$, de 25 de maio de 1995, que dispondo sobre consignações em folha de pagamento de servidores públicos civis da Administração Pública Federal, considera consignaçōes obrigatórias a reposição e a indenização ao erário (art. $1^{10}$, II, "e").

7. Manifesta sua divergência, nesse ponto, com a posição da antiga SAF e solicita o pronunciamento da Advocacia-Geral da União. Propõe "o entendimento de que todo valor recebido indevidamente seja objeto de reposição pelo servidor público, na forma do art. 46 da Lei 8.112, sem qualquer ressalva quanto a critérios de reposição anteriormente fixados. Propõe, ainda, seja expressamente declarada a insubsistência dos pereceres da Consultoria-Geral da República que dispu- 
nham de outra forma, inclusive o mencionado Parecer CGR/CR $n^{2} S A$ 121/88."

8. Submete ao $\mathrm{Sr}$. Advogado-Geral da Uniāo o processo que o levou a conhecer a orientação da antiga SAF, "em particular porque se trata de cumprir decisão judicial que envolve diversos Ministérios e órgãos da Administração Pública Federal (pleito relativo a reajustes em decorrência de planos econômicos) e a Procuradoria da União no $D F$, corretamente, propôs a reposição aos cofres da União em face da improcedência da ação..."

\section{II - A ORIENTAÇÃO OBSERVADA PELA ADVOCACIA-GERAL DA UNIÃO}

9. A antiga Consultoria-Geral da República, sucedida por esta Instituição, teve, por diversas vezes, oportunidade de manifestar-se sobre a questão da obrigatoriedade ou não da reposição de quantia indevida paga a servidores, em virtude de errônea ou má interpretação da lei pela Administraçāo. Em 1955, o eminente Consultor-Geral da República Themístocles Brandão Cavalcanti, já dizia:

"20. Quanto a esses efeitos, isto é, quanto à reposição das vantagens recebidas em conseqüência da interpretaçāo errônea dada à lei, parece-me que ela não se justifica, de momento que se incorporaram ao patrimônio dos beneficiários, que apenas se beneficiaram com o erro da Administração, de acordo com interpretação dada através de decreto executivo.

Houve boa fé presumida; não se trata, portanto de restituição do indébito, de momento que foi aplicado o decreto vigente ao tempo do pagamento." (Parecer $n^{2}$ X-29, D.O. 17/6/55, p. 11.894; destaquei).

10. Seguindo a esteira desse mesmo entendimento sucederam-se:

a) Parecer Z-260/57, da lavra do Dr. A. Gonçalves de Oliveira; D.O. 21/5/57, p. 12.852 (acumulação remunerada, desnecessidade de restituição dos vencimentos percebidos de boa fé);

b) Parecer H-180/65, da lavra do Dr. Adroaldo Mesquita da Costa; D.O. 27/5/65, p. 5.054 (importâncias pagas a maior-salário família. Percebidas de boa fé, não cabe a obrigaçāo de restituir);

c) Parecer SR-18/86, da lavra do Dr. Saulo Ramos; D.O. 24/12/86, p. 19.760 (pagamento de $13^{2}$ salário a servidores celetistas em serviço no exterior. Errônea interpretação da lei por parte da Administração. Desnecessidade de restituição);

d) Parecer SR-38/87, da lavra do Dr. Saulo Ramos; D.O. 30/10/87, p. 17.950 (Reposicionamento. Errônea interpretação da lei nāo justifica a reposição por parte de quem recebeu de boa fé a vantagem, mais tarde, considerada indevida);

e) Despacho SR-6, da lavra do Dr. Saulo Ramos; D.O. 18/8/88, p. 15.650. (Reposicionamento desfeito. Desconstituído o ato, não cabe a restituição das quantias recebidas de boa fé, em virtude de errônea interpretação da lei pela Administração).

11. Já na vigência da Lei n² 8.112, de 1990 , a Advocacia-Geral da União, mantendo a mesma orientação, pronunciou-se sobre $o$ assunto no Parecer GQ-114/97, da lavra do Dr. Geraldo Quintão (D.O. 26/11/96, p. $24.876 / 24.880$ ), quando se examinou a questão relativa ao valor das diárias percebidas a maior, de boa fé, por alguns servidores em estágio na Escola Superior de Guerra, em virtude de errônea interpretação da lei. Concluiu-se pelo não cabimento da restituição.

12. Não creio mereça reparos a orientação que vem sendo observada. A redação dos dispositivos das duas leis é equivalente. Como o art. 125 da Lei $n^{2} 1.711$, de 1952, os art. 46 e 47 determinam a forma pela qual as reposiçōes e indenizaçōes à Fazenda Pública são descontadas da remuneração do servidor. Não dizem quando, em que hipóteses, deve haver a reposição ou a indenização. A matéria é regulada pelo Direito civil: quem recebe o que não lhe é devido, fica obrigado à restituição (CC, art. 964); quem causa danos, deve indenizar (CC, art. 159). Se se trata, verdadeiramente de hipótese de recebimento indevido (reposição) ou de danos a reparar (indenização) é questão a ser decidida caso a caso. Aliás, isto ficou bem patente, não só no Parecer X-29 (item 9 supra), como, também, no 
Despacho no 6, de 1988, que aprovou o Parecer CGR/CR no SA-21/88, de cujo texto destaco:

"O servidor público que, de presumida boa $f e ́, v e n h a$ a receber alguma vantagem financeira, em decorrência de errada interpretação ou aplicação de norma legal, por parte da Administração, sem ter influenciado ou interferido na sua concessāo, independente de havê-la pleiteado ou não, jamais poderá vir a ser compelido, depois, a devolver aquelas importâncias, tidas por indevidamente pagas, porquanto descaracterizada a figura do indébito, em tais casos, nos quais o ato respectivo, embora vitimado de vício insanável, mesmo insuscetível de gerar direitos, goza de presunção de legalidade, até advir-lhe a nulificação, declarada pela autoridade, para tanto competente.

Isto é intuitivo e de inteira justiça.

Não se pode pretender penalizar o servidor, com o ônus da reposição, do que recebeu a maior indevido, depois de incorporado ao seu patrimônio, se ele não concorreu, direta ou indiretamente, para o erro administrativo, do qual foi beneficiado, ainda que isto assim o desejasse."

13. Do raciocínio lógico e do que se depreende dos pareceres citados, pode-se afirmar: a efetiva prestação de serviço, a boa fé no recebimento da vantagem ou vencimento, a errônea interpretação da lei e a mudança de orientaçāo jurídica são requisitos indispensáveis para que possa ser dispensada a "restituição de quantia recebida indevidamente". São cumulativos e não alternativos.

14. A efetiva prestação de serviço é essencial. Se o servidor não se enquadra na norma, se não presta efetivamente o serviço ao qual é destinada a vantagem e, ainda assim, a recebe, o pagamento é indevido e está sujeito à reposição.

15. A boa fé é a intenção pura, isenta de dolo, de engano, de malícia, de esperteza com que a pessoa recebe o pagamento "indevido", certo de que está agindo de acordo com o direito. Se um decreto, interpretando erroneamente um dispositivo legal, mandasse pagar determinada vantagem a certos servidores, é evidente que estes a receberiam de boa fé, desde que se enquadrassem na situaçāo nele descrita. Por outro lado, não se poderá dizer que há boa fé se, por exemplo, um servidor, exercendo um só cargo era um Ministério, tivesse, por erro no sistema SIAPE, seu nome incluído duas vezes na lista da mesma Secretaria de Estado ou na listagem de dois Ministérios e recebesse a mesma importância duas vezes. Não haveria, neste caso, interpretação errônea da Administração e posterior mudança de orientação. Não haveria a efetiva prestação de serviço referente aos dois vencimentos recebidos. Não haveria lisura no comportamento do servidor que, mesmo sabendo ser titular de um só cargo, recebesse duas vezes pelo mesmo serviço executado. Não agiria da mesma forma, isto é não permaneceria calado se a Administração the fizesse corte em seus vencimentos, se lhe deixasse de creditar a remuneração de um ou mais meses.

16. A errônea interpretação da lei deve estar expressa em um ato qualquer da Administração: uma norma legal de hierarquia inferior à lei (decreto, portaria instrução normativa), um despacho administrativo, um parecer jurídico que tenha força normativa. Da mesma forma, a mudança de orientação, após constatado o equívoco.

17. O conceito de pagamento indevido é muito simples, é óbvio, é cristalino: é aquele que não era devido à época em que foi feito. Ora, se o pagamento foi feito com base em um decreto, em uma portaria em uma instrução normativa, em um parecer com força normativa, é evidente que estava lastreado em algum instrumento, ate, então, válido. Não era então indevido; ao contrário, era devido em virtude da orientação adotada Só com a nulificação, após verificado o equívoco, deixou a orientação de ser obrigatória para a Administração. Foi, por exemplo, a hipótese de que cuidou o Parecer $n^{\circ}$ CGR/CR/SA-21/88, citado na peça vestibular destes autos. $O$ pagamento feito e, posteriormente discutido, estava baseado em um Decreto. Por isso, considerou-se que não era caso nem mesmo de repetição do indébito e não se determinou a restituiçāo porque o pagamento foi lícito durante a vigência do decreto.

18. A posterior mudança de orientaçāo, o 
equívoco verificado não invalida o pagamento feito, se o servidor se enquadrava na situação, se o recebeu de boa fé. O equivoco verificado tem dois efeitos: a) estancar o pagamento que vinha sendo efetuado; b) negá-lo a quem, na mesma situação, não o tenha ainda recebido. Isto foi claramente demonstrado no Parecer GQ-114-97, da lavra do Dr. Geraldo Quintão.

\section{III - O DECRETO N2 1.502, de 1995 CONSIGNAÇÕES EM FOLHA DE PAGAMENTO}

19. O Decreto $\mathrm{n}^{\mathrm{Q}} 1.502$, de 25 de maio de 1995, citado na peca vestibular deste processo pelo Sr. Consultor Jurídico e que dispōe sobre consignações em folha de pagamento de servidores públicos civis da Administração Pública Federal não o socorre na tese que defende.

20. Embora nāo o diga expressamente, na verdade o Decreto regulamenta o art. 45 da Lei $n^{2} 8.112$, de 1990 , que cuida de (a) consignações por imposição legal ou mandado judicial - caput, e (b) consignaçōes de pagamentos a terceiros autorizadas pelo servidor, a critério da Administração e com reposição de custos, na forma definida em regulamento - parágrafo único.

21. O Decreto nāo diz se a restituição deve ou não ser efetuada. Trata de consignações: diz, no art. 12, quais são as facultativas (as que se efetuam por consenso entre o consignante, o consignatário e a União, como, por exemplo, mensalidade de entidade de classe, associação, clube etc.) e quais as obrigatórias (decorrentes de lei ou de mandado judicial). Dentre as últimas, as obrigatórias, inclui as restituições e as indenizações. Restituiçōes e indenizaçōes, é claro, devidas, apuradas.

22. Não é matéria do Decreto dizer se a restituição deve ou não ser efetuada. A restituição é consequiência do recebimento indevido (CC, art. 964). Se é indevido ou não é questão a ser analisada e decidida caso a caso. Verificado o recebimento, mais tarde considerado indevido, passa-se a examinar se ocorreu a efetiva prestaçāo de serviço, se houve errônea interpretação ou aplicação da lei por parte da Administraçāo, se o pagamento estava baseado em um ato formal, se houve mudança de orientação após detectada a falha e, por último, se houve boa fé do servidor ao receber. Só então poder-se-á chegar à conclusão se o pagamento era ou não devido à época em que foi feito e sobre a obrigatoriedade ou não da restituição da quantia recebida

\section{IV - A SÚMULA DO TCU}

23. Em alguns dos Pareceres antes mencionados, cita-se a Súmula $\mathrm{n}^{\mathrm{Q}} 106$ do Tribunal de Contas da União, assim redigida:

"O julgamento, pela ilegalidade, das concessões de reforma, aposentadoria e pensão, não implica por si só a obrigatoriedade da reposição das importâncias já recebidas de boa fé, até a data da decisão pelo órgão competente."

24. Não implica obrigatoriedade de reposição das quantias já recebidas, porque pode ter havido (a) a errônea interpretação da lei por intermédio de um ato formal que concedeu a reforma, a aposentadoria ou a pensão, e (b) a boa fé do servidor no recebimento da importância.

\section{V - AS QUANTIAS RECEBIDAS EM VIRTUDE DE LIMINARES CONCEDIDAS PELA JUSTIÇA - REPOSIÇÃO}

25. Diz o Sr. Consultor que se trata de cumprir decisōes judiciais que julgaram improcedentes as ações (pleitos relativos aos planos econômicos) movidas por servidores contra a Uniāo, sendo que, antes, liminar, medida cautelar, ou tutela antecipada já haviam sido concedidas.

26. Entendeu-se no Ministério do Trabalho que as quantias recebidas não estavam sujeitas à reposiçāo, justamente em virtude dos pronunciamentos da extinta Consultoria-Geral da República posteriormente confirmadas por esta Instituiçāo no já citado Parecer GQ-I 14/97. 
27. Na verdade, os pronunciamentos mencionados nāo têm aplicação ao caso de que tratam estes autos. Há que fazer-se aí algumas observaçōes.

28. Em primeiro lugar, decisão judicial é para ser cumprida. Ao expediente encaminhado a esta Instituiçāo foram juntadas cópias do acórdāo e do voto condutor. Não se menciona se a restituição é ou nāo devida Mas deve-se frisar: a orientação hoje observada é válida, apenas, na esfera administrativa. Se a decisão judicial determinasse - o que não ocorreu a restituição ou a nāo restituição, deveria ela ser cumprida tal qual nela expresso.

29. Mas, ainda que nada tenha sido determinado, a restituição no caso dos autos é devida. A açāo proposta pelos servidores visava ao recebimento de importâncias que entendiam devidas em consequiência dos planos econômicos do Governo. A liminar determinou o pagamento, mas decisāo final julgou improcedente o pedido feito pelos servidores. A decisão liminar era provisória e estava sujeita à reforma. Cassada com a decisão definitiva perdeu sua eficácia.

30. Não se enquadra a hipótese nos pronunciamentos desta Instituição. O simples fato de haver uma ação judicial significa que a União, que a Administração não estava de acordo com o pagamento pleiteado, tanto que a ele foi compelida por decisāo liminar. Nāo houve errônea interpretação da lei pela Administração. Não está presente, no caso, um dos requisitos referidos no item 13.

31. Além disso, se a ação proposta pelos servidores foi julgada improcedente, significa que a interpretação dada pela Administração (o não pagamento) era correta Não houve mudança de orientação. $O$ pagamento não foi feito espontaneamente pela Administração que o entendia indevido. Não está presente outro requisito mencionado no item 13 . Não havia, no caso uma decisão administrativa a lastrear o pagamento.

32. Houve, na verdade, um pagamento indevido. E indevido, judicialmente proclamado com a decisão final. Em conseqüuencia, a restituiçāo do pagamento feito mediante limi- nar deve ocorrer: a sentença definitiva anula a liminar e restabelece o status quo anterior. Frise-se que nāo se pode dizer que o pagamento era devido em conseqüência da decisão liminar que era provisória e estava sujeita à reforma com as conseqüências judiciais dela resultantes.

33. Deve-se frisar que a liminar só e concedida na existência do fumus bonus juris e na urgência em resguardar este sinal do bom direito que se perderia se se tivesse que esperar decisão final. É o caso de candidato que presta concurso, mediante liminar contra o indeferimento de sua inscrição. Nāo fosse a liminar não poderia prestar as provas. $O$ concurso seria realizado e o candidato perderia seu "possível" direito. No caso dos autos, nāo havia risco de que se perdesse o direito pleiteado. Ao requerer a liminar, os servidores correram o risco de ver cassada a decisão provisória. Por precaução, deveriam manter intacta a quantia recebida para posterior devolução, no caso de perda da ação.

\section{VI - CONCLUSÃO}

34. Como se viu, a orientação até agora adotada por esta Instituição quanto ao não cabimento de restituição na hipótese de pagamento indevido a servidor que o recebeu de boa fé e em virtude de errônea interpretação ou má aplicação da lei pela Administração, não está a merecer reparos. Deve ser mantida.

35. A efetiva prestação de serviço, a boa fé no recebimento da vantagem ou vencimento, a errônea interpretação da lei expressa em um ato formal e a mudança de orientação jurídica são requisitos indispensáveis para que o pagamento feito possa ser considerado válido e, à época, devido, não estando sujeito à restituição.

36. No caso de que tratam estes autos decisões judiciais que, cassando liminares, julgaram improcedentes ações propostas por servidores contra à União - deve ser observado o que dispõe a sentença, se o dispõe. Se 
o julgado nada explicita - como não deveria explicitar - a restituição é devida, por inexistirem, no caso, todos os requisitos imprescindíveis à aplicação do entendimento já consagrado por esta Instituição. A hipótese de pagamento feito mediante liminar posterior- mente cassada configura pagamento indevido sujeito à reposição.

37. É o que me parece, s. m. j. À consideração superior.

Brasília, 3 de agosto de 1998

MIRTÔ FRAGA, Consultora da União 